\title{
Maternal communicative style in interaction with infant siblings of children with Autism
}

\begin{abstract}
Functional aspects of infant-directed-speech (IDS) in face-to-face interaction play a central role in infant development (Venuti et al. 2012) and are important in shaping infant responsiveness (Goldstein et al. 2003), yet have rarely been examined and there is little consensus on specific infant outcomes. Infant siblings of children with autism are at increased risk of developing this disorder characterised by socio-communicative impairments and present particular challenges for parents in interaction. Using a prospective video analysis design, we had two objectives: to investigate maternal functional speech styles in interaction with these infant siblings; and to analyse the relationship between maternal functional style and infants' cognitive, language and socio-communicative development. We found significantly lower rates of maternal responsive-contingent utterances to the infant siblings and significant associations between maternal IDS and infant test scores only for the typical dyads.
\end{abstract}

Key words: Maternal infant-directed-speech; Infant responsiveness; At-risk-for-autism siblings; Cognitive and language outcomes.

\section{Introduction}

This study is situated in research on mother-infant interaction, considered to be a co-constructed process between mother and infant (Beebe \& Lachmann 2002) where each partner influences the behaviour and reactions of the other. Maternal infant-directed-speech (IDS) within the context of that interaction is dynamic in nature, is adapted to the changing needs of the infant (Ko 2012) and is critically important for many aspects of infant development, in particular for language acquisition (see for instance, Soderstrom 2007). A recent meta-analysis of IDS and Child Directed Speech (CDS) studies by Meyer et al. (2011) confirmed the supporting role of CDS for language acquisition in children, although concluding it is not a necessary prerequisite. There is debate as to the exact mechanisms and linguistic properties by which this facilitative effect is achieved and only a few studies have empirically compared infant language learning from either IDS or adult-directed-speech, (Ma et al. 2011; Singh et al. 2009; Thiessen, et al. 2005)). Nonetheless, IDS is generally considered to act as a catalyst in the course of language acquisition and is also the "first and arguably the most important factor related to successful language development encountered by the infant' (Matychuk 2005:368).

According to Saint-Georges (2011: 67) IDS fulfils four main functions: communication of affect; facilitation of social interaction through infant preference; engaging and maintaining infant attention; and facilitation of language acquisition. Several studies (Feldman 2007; Hsu \& Fogel 2001; Trevarthen \& Aitken 2001) of both normal and atypical language development have implicated interpersonal variables as important predictors of language outcomes. Further, the functional or 
pragmatic aspects of maternal speech in particular have been identified as playing a central role in infant development (Venuti et al. 2012) and may be particularly important in shaping the infant's responsiveness (Masataka 2003), yet few studies have examined this aspect of IDS. Mother's style of interaction may strengthen either the phonetic or the prosodic qualities of the infant's vocalisations and can impact on the frequency, complexity and intensity of infant vocalisations (Goldstein, King, \& West 2003; Gros-Louis et al. 2006; Masataka 2003). Equally, maternal style may have developed in response to the infant's particular characteristics (Spiker, Boyce, \& Boyce 2002), and maternal response type is related to earlier responsiveness on the part of the infant (Masataka 2003:155). It is in the context of this mother-infant interaction, throughout the first year, that many of the critical precursors of socio-communication and language development will appear, such as joint attention, looking behaviours and pointing. These behaviours are often identified as missing or impaired in individuals with autism spectrum disorder (ASD) and as a result, autistic infants are likely to experience some deficits in their linguistic environment, partly because they afford their interactional partners less opportunities for responsiveness (Mahdhaoui et al. 2011). Parents have reported a lack of initiative and responsive behaviours on the autistic infant's part, particularly toward the end of the first year, to which they have tended to respond with increased solicitation behaviours (Saint-Georges et al. 2010:1).

ASD is a highly heritable neurodevelopmental condition (Ozonoff et al. 2011 reported a familial recurrence risk of 18.7\%), and evidence of an early difference in socio-communicative and language behaviours has been found in at-risk infants (defined as having one or more older siblings with the disorder) as well as in autistic children (Bedford et al. 2012). It is possible that there may also be a pattern of disrupted interaction between infant siblings of children with autism and their mothers. The development of siblings of children with autism is being comprehensively studied, including by worldwide consortiums (see, for example, Cassel et al. 2007; Elsabbagh \& Johnson 2010; Gamliel et al. 2009; Rogers 2009; Seidman et al. 2010; Zwaigenbaum et al. 2009). As yet, not that much is known about the behaviour of mothers of at-risk infants and the extent to which it is influenced by interactions with the infants' older autistic sibling(s), by expectations and anxieties about the prospects of the at-risk infant, or by the infant's own patterns of initiating, attending and responding behaviours. These infant siblings are at risk of developing a behaviourally-defined disorder characterised by socio-communicative impairments that is difficult to reliably diagnose before 18 months and, as such, present particular challenges for parents in interaction.

There have been some investigations of maternal interactions and behaviour with these later born siblings of children with ASD. Doussard-Roosevelt et al. (2003) found that the maternal adjustments made with the child with ASD in the family did not have an effect on interactions with their non-ASD children but only maternal approach characteristics and play behaviours with preschoolers were analysed. Meirsschaut, Warren, \& Roeyers (2011) in a within-family study found mothers differentiated in their responsiveness but not in their initiatives towards their ASD and non-ASD 
children. Only a few researchers have specifically investigated the language environment of infants at-risk for autism, and only some of them included prelinguistic infants. Jakubowski \& Iverson (2011) analysed mothers' speech to 18 month old at-risk infants and found their mothers addressed only half as much speech to them as the control mothers and used twice as many attention-getting utterances. They concluded that having an older child with autism may well impact mothers' behaviour with their later born children, even in the absence of any obvious autistic symptomatology. Wan et al. (2012) studied parent-infant interaction with 6-10 month old at-risk infants and reported higher rates of maternal directiveness and lower rates of sensitive responding. In de Falco et al.'s study (2011) mothers of children with ASD referred more to themselves, named their children more often, used more directives and posed less questions than the mothers of typically developing (TD) and developmentally delayed (DD) children. It has also been reported that mothers of ASD children used more high-intensity approach behaviours and more prompts, both verbal and non-verbal, to get the child's attention (Doussard-Roosevelt et al. 2003; Meirsschaut et al. 2011).

Interaction strategies could generalise to communication with later-born at-risk siblings. Negotiation between caregiver(s) and infant is central to IDS (Matychuk 2005:301). A mother interacting with her infant does not plan what she will say or do but responds and adjusts her behaviours on a second-bysecond basis to her infant's cues. If mothers are anxious that this child may also be on the autistic spectrum, they may be tailoring their IDS to address the characteristic impairments encountered in ASD and in their older child(ren): problems of engagement, joint attention, eye contact. It is also possible that the infant is largely responsible for any observed differences in mother's IDS (Mahdhaoui, Chetouani, Cassel, Saint-George, Parlatto, et al., 2011) or even that both mother and infant are behaving differently. Mother's conversational style is not the cause of the infant's difficulties but given that parental responsivity and sensitivity has been related to subsequent development of communication skills in children with autism (Siller \& Sigman, 2002, 2008) and to outcomes in language intervention in children with ASD (Yoder \& Stone, 2006) it is an important mediating factor to consider.

Although it has been established that IDS is beneficial for infant development, there is little consensus as to the outcomes associated with alteration and adaptation of maternal communicative style, in particular in the case of ASD. For example, frequent redirection and solicitation rather than following the infant's focus of attention has been shown to hinder typical language acquisition (e.g. Tomasello \& Farrar 1986) and to demand a shifting of attention that is difficult for children with ASD (Landry \& Bryson 2004), but in the early months, infants have also been shown to benefit from directive structuring of their play (Pine 1992; Saxon 1997; Tamis-LeMonda \& Bornstein 1989). Carpenter $e t$ al. (1998) found that the degree to which mothers used language that followed their TD infant's attention predicted the infant's earliest gestural and linguistic skills. However Kasari et al. (2012) have found that pointing and gestures that direct the child's attention had long-term beneficial effects on language development in autistic preschoolers and Parladé et al. (2010) reported that maternal 
persistence in relation to engaging the autistic infant's attention seemed to promote joint attention development.

In this context, two main goals were identified for this study:

- To investigate if maternal functional speech styles in interaction with later born at-risk siblings (HighRisk, HR) would be the same as documented with older autistic child(ren); specifically, that mothers of HR infants would use more attention solicitation practices, less questions and produce less contingently responsive utterances than mothers of infants with no known risk factors ( Low-Risk, LR);

- To analyse the relationship between maternal IDS functional style and infants' cognitive, language and socio-communicative development.

The first goal is driven by the hypothesis that the mother's IDS to their at-risk infants will mirror many aspects of their interaction with the autistic sibling, and that this may be due to (1) the mother's anxieties about the risk-status of the infant; and/or (2) impaired reaction???? by the infant due to ASD. It is beyond the scope of this paper to determine whether it is the mother's anxieties and/or the infant's lack of responsiveness that impact on any altered maternal IDS that may be found. The second goal of the study is to analyse the potential impact of maternal IDS on the child's cognitive, language and sociocommunicative outcomes. This is based on the hypothesis that any altered IDS on the part of the mother of at-risk infants will impact differentially on child outcomes.

\section{Method}

\subsection{Participants}

Recruitment of infant siblings is difficult, given the sensitive nature of the premise that an infant is at increased risk of a developmental disorder and, in this case, the level of commitment required from participating families. While an equal number of closely matched sets of mothers and infants was the goal, the amount of data generated from multiple data-collection time-points and assessments in a longitudinal study may counteract somewhat the heterogeneity of the resultant participant groups. However it is important to note that group results and statistical comparisons in this context must always be interpreted with caution.

Sixteen Irish English-speaking mothers and their seventeen infants were recruited through a national parenting website and clinical health services: ten infants ( $7 \mathrm{~m}$; $3 \mathrm{f}$ ) with no known developmental risk factors, without an autistic sibling and with no family history of ASD (Low-Risk LR) and seven infants ( $2 \mathrm{~m}$; 5f, including one set of monozygotic twin girls) at genetic risk for ASD, defined as having at least one older sibling(s) with a clinical diagnosis of ASD (High-Risk HR). Although the ratio was accidental, given the overrepresentation of boys in both ASD diagnosis and the research 
literature, it was of interest to include girls who have been relatively neglected. The data generated with the pair of at-risk twins served to validate the observational method used, as analysis showed the mother to be very similar in her language behaviour with both infants. We interpreted that as an indication that the behaviours elicited by the testing condition were relatively natural and also reflected aspects of the mother's individual speech style.

The mean age of the infant at the time of the first visit was 3.7 months for the LR infants (ranging from 3 to 5 months) and 5.2 months for the HR infants (ranging from 3 to 7 months). Mothers recruited were well matched on those factors known to be the most important in relation to their influence both on maternal speech styles and in relation to their mediated impact on infant cognitive and language development, namely, maternal age, socio-economic status and level of education. The mean age of mothers at the birth of the infant was 34 years for LR mothers (range of 28-38 years) and 35 years for HR mothers (range of 28-40 years). All the families were low-to-middle-SES and mothers had from secondary/high school to university education.

\subsection{Procedure}

Using a prospective video analysis (PVA) design, mother-infant dyads were filmed in face-to-face interaction once every four weeks mostly in their own home but occasionally in the university in a relaxed environment with which they were familiar. Filming occurred between the ages of approximately 3 to 12 months for each infant but not all dyads have data for every month. Of the HR group, five dyads have data for 8 or 9 months, one dyad was filmed 7 times and one dyad had 5 visits. All LR dyads have data for 9 months, except for 1 missed session.

The mothers were asked to interact with their infant as they would normally and were not provided with any toys or props, although some used books or toys on occasion. Although a completely natural environment could not be created, conditions created were reasonably conducive to obtaining naturalistic behavioural information. Most sessions took place in the family home (80\%) and analysis revealed no differences between sessions according to location of filming. All filming and testing was conducted by the second author who over the period of participation developed a rapport with the families. Maternal behaviour and style (for example, primarily affective or informational in orientation, rate of loquaciousness) was remarkably stable across time for each dyad and it was felt that the samples obtained reflected each dyad's interaction patterns well.

Mother and infant were filmed alone in the room for up to 15 minutes, of which five minutes was selected for analysis. In the case of the twin infants, the mother was filmed with each twin individually, with a long break between sessions. The first 3 minutes of footage were not used for coding as this period was viewed as the time during which the mother and infant were adjusting to the filming set-up and the absence of the researcher and during which mother and infant began to establish the interaction. After that period, the next 5 continuous minutes of interaction where the infant was not fussing or crying were selected for analysis. 
A total of 144 mother-infant unstructured face-to-face interactions were coded, blind to dyad status or information, amounting to an average of 39.3 minutes in total per HR dyad and 44.5 minutes for the LR dyads. All audible maternal vocalisations directed to the infant were coded by three research assistants using the Observer XT (version 7). The coding unit was defined as an utterance with a single functional category, and the unit changed when there was a change in coded utterance type or when an utterance terminated and a silence of at least 2 seconds followed. Therefore, a minimum unit size could be a single word or the sound of a letter, for example, hi, a, aha, e or goo (Penman et al. 1983; Bornstein et al. 1992).

\subsection{Maternal utterance classification}

A total of 14,223 utterances were coded excluding fillers and non-meaningful words. All maternal utterances were initially classified into one of 19 mutually exclusive categories according to the communicative function of the utterance (using a taxonomy adapted from Paavola et al. 2005, see Table 1). Every utterance was coded to one of the functional classifications but not every mother produced every functional type at each visit. Coders were trained to a high level of reliability on maternal utterances (88\%). Twenty percent of 144 videos were randomly selected and analysed independently by three research assistant coders. The percentage of agreement in categorizing maternal utterances was $87 \%$. The three main functions analysed in relation to the specific hypotheses were:

- Attention-soliciting utterances designed to elicit and to regulate the infants' attention;

- Interrogatives: yes/no, test questions, permission requests, information requests, clarification requests;

- Responsive utterances to the infant contingent upon, or responsive to, the infant's behaviour. To be conservative, only those utterances that were, by their functional definition, contingent upon infant behaviour (commands/warnings, negations/criticisms, affirmatives, and imitations) were classified and analysed as responsive speech.

\section{INSERT TABLE 1 HERE}

We employed time-budgeted interaction and each function was calculated as a proportion of mothers' total speech input to her infant. We assumed that the amount of speech produced impacts the distribution of each functional type (although not necessarily in a directly linear association). Our interest in the relative distribution of functional types in each mothers' total input to the infant and in the infants' levels of exposure to maternal IDS styles, dictated proportional representation as the 
appropriate unit of measurement (see Yoder \& Symons (2010:75) for a full discussion and rationale for use of proportion as metric).

\subsection{Infant testing protocol}

Each infant was administered the cognitive and language tests of the Bayley Scales of Infant Development-Third Edition (BSID-III) at 12 and 18 months. The resulting Cognitive and Language Index and Subscale scores were used for comparison between and within groups. The Early Social Communication Scales (ESCS) (Mundy et al. 2003, a measure of non-verbal social communication skills for children up to age 30 months) was also administered to each infant at 12 and 18 months. Administration of the ESCS was video-recorded and behavioural ratings were obtained by trained observers. Testing lasted 22 minutes on average. One research assistant coded each ESCS with a trained coder until they reached a reliability of at least $85 \%$. Subsequently, $20 \%$ of all videos were coscored and the average inter-rater reliability was $87 \%$.

\subsection{Data Analysis}

The distribution of maternal utterance types was non-normal and showed heterogeneity of variance (Shapiro-Wilks tests, p's $<0.05$; Levene's test, p's $<0.05$ ). Non-parametric one-tailed tests were used throughout: Mann-Whitney U, Kendall's tau correlations, using PASW Statistics 18. Because of the small sample size, Bonferroni correction was not made as part of the statistical analyses.

\section{Results}

The functional distribution of the speech addressed by the two groups of mothers to their infants was very similar overall in terms of quantity and proportionate representation of each functional category. The average amount of time the mothers spent vocalising to their infant in any given session was almost identical between groups (HR 178.43 secs.; LR 180.13 secs.) and the total quantity of utterances did not differ significantly between groups, (LR, $M=916, S D=223.38 ; H R, M=722.86$, $\mathrm{SD}=244.03)$.

\subsection{Functional aspects of maternal IDS}

There were few significant differences between groups on distribution of functions of maternal speech to infants when analysed by risk status. The hypothesis that mothers of HR infants would use more attention solicitations was not supported ( $U=20, z=-1.46, n s)$, although mothers of high-risk infants produced proportionately more than twice as many attention-solicitation devices as mothers of LR infants. In relation to the hypothesis of less questions addressed to HR infants, mothers of high-risk infants in this study produced slightly fewer questions, though the difference was not significant ( $U=34, z=-.09$, ns). The final hypothesis that HR infants would hear less directly responsive utterances was supported: mothers of low-risk infants $(\mathrm{Mdn}=0.18)$ were significantly more likely than mothers of high-risk infants $(\mathrm{Mdn}=$ 
0.13) to produce speech that could be considered directly responsive to or directly contingent upon infant behaviour $(\mathrm{U}=14, \mathrm{z}=-2.05, \mathrm{p}<.05)$.

\subsection{Outcome association measures}

This section reports on the associations between the functions of maternal speech input and infant test scores (cognitive and language index and subscale BSID-III scores) aged 12 and 18 months (see Table 2). Nonparametric correlations and tests of significance were used to examine the relationship between maternal speech factors and infant test scores in the two risk-category groups.

\section{INSERT TABLE 2 HERE}

All maternal speech variables were correlated with infant tests score using Kendall's Tau-b. Only significant and systematic findings are reported here. There were few strong associations between the communicative functional profile of maternal speech to infants from three to 12 months of age and their infants' language and cognitive outcomes aged 12 and 18 months. Any significant associations found between maternal IDS and infant test scores were found for the LR dyads only. Mothers' responsive speech, which was significantly more frequent for mothers of LR infants, was positively correlated with overall language outcomes at 12 months (Kendalls tau- $b=.70, p<.01$ ) and with the infants' Receptive Language Subscale scores (Kendalls tau-b=.58, $\mathrm{p}<.05$ ). The proportion of attention-solicitations in maternal input was significantly and negatively associated with both language outcomes at 12 (Kendalls tau- $b=-.61, \mathrm{p}<.05$ ) and 18 months (Kendalls tau-b=-.63, $\mathrm{p}<.05$ ) and with cognitive outcomes aged 18 months (Kendalls tau-b=-.62, $\mathrm{p}<.05$ ) but again for the low-risk infants only. Mothers' questions to LR infants were negatively associated only with the subscale of expressive language at 12 months (Kendalls tau-b=-.75, $\mathrm{p}<.01$ ). There were no significant associations found for the high-risk mother-infant dyads for any maternal variables.

\subsubsection{Early Social Communication Scales (ESCS).}

There were no statistically significant differences between groups for scores on the ESCS measure (see Table 3) but group patterns were evident. Scores for Initiating Joint Attention (IJA) aged 12 months were very similar between HR and LR groups but by 18 months IJA and Initiating Behaviour Requests (IBR) were consistently lower for the HR infants. Scores for Responding to Joint Attention (RJA) were highly similar at 12 months but by 18 months, the HR infants had lower rates of RJA. It should be noted that although differences are only evident for these behaviours at 18 months (but are not statistically significant), that does not allow us to conclude that these and other related behaviours not measured in this study, for example, contingent responding, were not already presenting differently at 12 months. 
INSERT TABLE 3 HERE

\section{Discussion}

Our first aim was to investigate whether the functional speech patterns of maternal interaction with autistic children would generalise to interactions with later born at-risk infant siblings. Our findings fit with some but not all of those reported in the literature in relation to this high-risk cohort. Jakubowski \& Iverson (2011) reported that mothers of the HR infants in their study produced approximately $50 \%$ fewer utterances than mothers of LR infants but both groups of mothers in our study addressed equal amounts of speech to their infants (albeit within a wide range).

Specifically we predicted that mothers of HR infants would use more attention solicitation practices, less questions and less contingently responsive utterances than mothers of their LR counterpart infants. Although overall very similar communicative functionality was expressed in face-to-face interaction by both groups of mothers, we could observe different distributional profiles. Lower rates of contingently responsive utterances, higher rates of attention-solicitation utterances and approximately equal rates of questions were observed for the HR dyads. Therefore, some of the patterns found in ASD mother-child dyadic interaction are also present in the interaction between at-risk infants and their mothers.

Starting from the well-established finding that mothers in general tend to be highly responsive to their infants, true of both groups in this study also, we speculate that the significantly lower rate of directly responsive or contingent-by-definition maternal utterances found in the speech of the mothers of the HR infant group may be as a result of the infants being less active and less responsive in general and so therefore providing less opportunity for verbal maternal commentary and response. Wan et al. (2012) recorded lower rates of liveliness in their HR infant group, as did Mahdhaoui et al. (2011) who reported a decrease in infant activity from 6 months onwards. In addition, mothers of low-risk infants produced over twice as many negations or criticisms as mothers of high risk infants. This profile of low-risk maternal verbal input implies a lot more activity on the part of the LR infant than the HR infant. The LR infants may have engaged in joint attention (JA) bids more often (they had higher IJA scores as measured by the ESCS than the HR infants) so mothers were able to engage more often in triadic intersubjective attention. The proportion of attention-getting utterances was not significantly different between groups in this study but these devices were a more prominent feature of the mothers' speech to their HR infants relative to the LR group. Our findings that the mothers of HR infants in our study were more likely to focus on the infant's attention matches findings from Jakubowski \& Iverson's (2011) study.

Our prediction that the mothers of HR infants would use fewer questions was not borne out. Overall the mothers' rate of questions was very similar and only slightly lower for the mothers of HR infants.

However, mothers of LR infants posed twice as many types of question that demanded some form of interaction or response and so sought the active participation of the infant, in the information-salient style 
described by Masataka (2003). On the other hand, the mothers of HR infants tended to check their own understanding more often through request clarification utterances, a profile not unlike that of the fathers of typically developing (TD) infants in Tamis-LeMonda's study (2012) who were deemed less likely to understand the infant's vocalisations. Thus while the mothers of HR infants in this study look somewhat different to the mothers of LR infants and mothers of developmentally delayed (DD) infants in other studies, they look somewhat like fathers of TD infants. To our knowledge there has been only one study comparing maternal and paternal speech to their children with ASD (Venuti et al. (2012), who found qualitative but no quantitative differences) and no study of fathers' speech to HR infants. More studies comparing parental speech input would be interesting in this context.

A clear prodrome for diagnosis of autism in infancy has not yet been defined (see Yirmiya \& Charman (2010) for a status review) and it remains difficult to reliably and robustly identify behavioural markers at either individual or group level for autism before 12 or even 18 months. Parental report on the infant is very important and a crucial source of information but it may also be productive to try to locate markers in the adaptive responsive behaviour of the adults who interact with these infants continually. By analysing those intuitive, non-conscious aspects of parenting that are nonetheless critical for development it may be possible, together with the red flag behaviours identified in the infants themselves, to use maternal behaviours in interaction to help identify dyads at-risk in a bid to intervene as early as possible. SaintGeorges et al. (2011:11) have proposed asking concerned parents about their style of interaction with their infant, specifically with regard to a hyper-stimulating style, which they propose is a response to an underactive infant. It may be that the mother who feels something is wrong is basing this intuition on her own behaviour as afforded by the infant, rather than on any specific behaviour manifested by the child. Our second aim was to analyse the relationship between maternal IDS functional style and infants' cognitive, language and socio-communicative development with a view to assessing the predictive validity of maternal speech functions for infant outcomes. Findings from this study accord well with those of Venuti et al. (2012) with TD, DD and ASD infant-mother pairs. We found a high degree of similarity in maternal functional language to the two groups of infants and very few significant associations between maternal style and infant outcome measures. No significant associations could be found for the high-risk mother-infant dyads yet significant associations were found for the LR dyads on the three functions under investigation: maternal responsiveness, questions and attention-solicitations. Mothers' of LR infants questions were negatively associated with infants' expressive language at 12 months, as were her attention solicitation bids with LR infant language and cognitive test scores at 18 months. This suggests that the increased incidence of attention-solicitations addressed to the high-risk infants is not having a detrimental effect on developmental outcomes as it appears to have for low-risk infants and may therefore have a place in intervention and training programmes. This finding reinforces the need to do fine-grained contextual analyses before concluding that any particular style of interaction or IDS is inherently negative or beneficial in its effects (as discussed by Pine 1992). Second, mothers' of LR infants responsive speech was positively associated with overall language scores aged 12 months, particularly with receptive 
language, and with initiating joint attention at 12 months. However we interpret this association as a further reflection that the infants at low-risk are more active, engaged and responsive and so are provoking more responsive speech from the mother in turn. According to Swenson, Fein \& Naigles (2008) it is not the mothers' usage of particular speech acts that facilitates language but rather language development is facilitated only when the child is actively engaged during the utterance. This lack of engagement is a feature of emergent autism as characterised by atypical social perception patterns, social-communication skills and visual attention preferences (Elsabbagh et al. 2011). For example, Klin (1991) found that infants with ASD lacked the typical listening preference for mothers' voice. An analysis of the infants' responses to maternal vocalisations is currently being prepared which will investigate HR infants' patterns of responsivity and engagement to maternal behaviours such as attention solicitations and calling the infant's name.

\subsection{Limitations}

The findings discussed here are based on group results and, given the complex heterogeneity and variation at all levels of analysis in autism (Waterhouse 2012), must be interpreted with caution. Few statistically significant differences were found, perhaps partly due to the combination of small sample size coupled with the large individual variation that is also a feature of language and of IDS in general. It is increasingly acknowledged for these domains that variability needs to be analysed as an important source of information, both within individuals and across time, rather than treated as a nuisance variable or smoothed out (Dereu et al. 2012; van Geert \& van Dijk 2002). The small sample size does not allow for robust statistical analysis but this is offset somewhat by the longitudinal data collected and by the observation that mothers' profiles were very stable. By recording across multiple sessions it was ensured that mothers were familiar with the researcher and the testing set-up and her behaviour was not overly affected by being filmed.

No significant differences were found in the quantity of speech addressed to the infant groups in face-toface interaction, unlike some studies, but Mahdhoaui et al. (2011) has shown that infants who will be diagnosed with autism begin from about 6 months on to display decreased rates of responsive behaviours and social initiatives towards their caregivers and so will likely experience cascade effects and relative deficits in their linguistic environment over time. In this study, mothers of HR and of LR infants were equally vocal but it would be very useful to gather information using, for example, the Language Environment Analysis (LENA) system on the quantity and quality of everyday interactions in the home over a period of time to try to capture this trajectory.

Acknowledgements: This work was funded by the Irish Research Council for the Humanities \& Social Sciences (IRCHSS). 
Table 1: Comparison of mean proportion of functional utterances of mothers of $L R$ versus mothers of HR infants.

\begin{tabular}{|c|c|c|}
\hline Risk status & Low-Risk $(\mathrm{n}=10)$ & High-Risk $(n=7)$ \\
\hline Function of utterance & Mean (SD) & Mean (SD) \\
\hline Naming object & $.034(.033)$ & $.037(.040)$ \\
\hline Mand model & $.008(.006)$ & $.005(.009)$ \\
\hline Description & $.151(.056)$ & $.115(.074)$ \\
\hline Displaced speech & $.003(.003)$ & $.006(.010)$ \\
\hline Tag & $.014(.009)$ & $.012(.008)$ \\
\hline Compliment & $.016(.010)$ & $.019(.015)$ \\
\hline Filler & $.110(.043)$ & $.113(.034)$ \\
\hline Non-speech & $.112(.063)$ & $.142(.081)$ \\
\hline Song & $.028(.020)$ & $.048(.061)$ \\
\hline Social play & $.102(.054)$ & $.122(.057)$ \\
\hline Conventional social expre & $.030(.020)$ & $.024(.013)$ \\
\hline Attention solicitation & $.029(.017)$ & $.074(.054)$ \\
\hline Responsive utterances & $.178(.049)$ & $.133(.034)^{*}$ \\
\hline Affirmative & $.051(.040)$ & $.023(.011)$ \\
\hline Imitation & $.033(.023)$ & $.035(.010)$ \\
\hline Command/warning & $.067(.030)$ & $.063(.030)$ \\
\hline Negative/criticism & $.027(.020)$ & $.012(.010)$ \\
\hline Interrogative utterances & $.182(.039)$ & $.169(.070)$ \\
\hline Yes/No question & $.018(.013)$ & $.024(.024)$ \\
\hline Test question & $.067(.031)$ & $.048(.036)$ \\
\hline Permission request & $.023(.007)$ & $.033(.013)$ \\
\hline Request information & $.051(.018)$ & $.039(.044)$ \\
\hline Request clarification & $.021(.024)$ & $.024(.023)$ \\
\hline
\end{tabular}

*p<.05 
Table 2: Bivariate relations between maternal language functions and infant Bayley-III language and cognitive index scores for $L R$ versus HR groups.

\begin{tabular}{lllll}
\hline & \multicolumn{2}{c}{ Language score } & \multicolumn{2}{c}{ Cognitive score } \\
Maternal function & \multicolumn{2}{c}{ tau-b } & \multicolumn{2}{c}{ tau-b } \\
Question & LR & HR & HR \\
12 months & -.07 & -.48 & -.37 & -.31 \\
18 months & -.24 & -.29 & .24 & -.10 \\
& & & & \\
Attention & LR & HR & LR & HR \\
12 months & -.48 & .19 & -.07 & -.04 \\
18 months & $-.72 *$ & .13 & $-.77 * *$ & -.70 \\
& & & & \\
Responsivity & LR & HR & LR & HR \\
12 months & $.70 * *$ & -.37 & .32 & -.41 \\
18 months & -.14 & -.29 & .24 & .21 \\
\hline p $<.05 ; * * \mathrm{p}<.01$ & & & &
\end{tabular}

Table 3: Median ESCS scores for infants aged 12 and 18 months by group status.

\begin{tabular}{lllllllll}
\hline Status & $\begin{array}{l}\text { IJA } \\
\mathbf{1 2} \text { month }\end{array}$ & RJA & IBR & RBR & $\begin{array}{l}\text { IJA } \\
\mathbf{1 8} \text { month }\end{array}$ & RJA & IBR & RBR \\
\hline $\begin{array}{l}\text { Low-risk } \\
\mathrm{n}=10\end{array}$ & 17 & 0.5 & 28 & 0.4 & 16 & 0.9 & 36.5 & 0.4 \\
$\begin{array}{l}\text { High-risk } \\
\mathrm{n}=7\end{array}$ & 17 & 0.4 & 19 & 0.4 & 11 & 0.5 & 29 & 0.5 \\
\hline
\end{tabular}

IJA: Initiating joint attention; RJA: responding joint attention; IBR: Initiating behavioural request; RBR: responding to behavioural requests. 


\section{REFERENCES}

Bayley, N. (2006). ( $3^{\text {rd }}$. Ed.). Bayley scales of motor and mental development. Psychological Corp: Harcourt Assessment.

Bedford, R., Elsabbagh, M., Gliga, T., Pickles, A., Senju, A., Charman, T. \& Johnson, M.H. (2012). Precursors to social and communication difficulties in infants at-risk for autism: Gaze Following and attentional Engagement. Journal of Autism and Developmental Disorders 2(10), 2208-2218.

Bornstein, M., Tal, J., Rahn, C., Galperin, C., Pecheux, M., Lamour, M. ... \& Tamis-Lemonda, C. (1992). Functional analysis of the content of maternal speech to infants of 5 and 13 months in four cultures: Argentina, France, Japan, and the United States. Developmental Psychology 28, 593-603.

Carpenter, M., Nagell, K. \& Tomasello, M. (1998). Social-cognition, joint attention, and communicative competence from 9-15 months. Monographs of the Society for Research in Child Development 63.

Cassel, T.D., Messinger, D.S., Ibanez, L.V., Haltigan, J.D., Acosta, S.I. \& Buchman, A.C. (2007). Early social and emotional communication in the infant siblings of children with autism spectrum disorders: An examination of the broad phenotype. Journal of Autism and Developmental Disorders 37, 122-132.

de Falco, S., Venuti, P., Esposito, G. \& Bornstein, M.H. ( 2011). Maternal and paternal pragmatic speech directed to young children with Down syndrome and typical development. Infant Behaviour Development 34(1), 161-9.

Dereu, M., Roeyers, H., Raymaekers, R. \& Warreyn, P. (2012). Exploring individual trajectories of social communicative development in toddlers at risk for autism spectrum disorders. Research in Autism Spectrum Disorders 6, 1038-1052.

Doussard-Roosevelt, J.A., Joe, C.M., Bazhenova, O.V. \& Porges, S.W. (2003). Mother-child interaction in autistic and non-autistic children: Characteristics of maternal approach behaviours and child social responses. Development and Psychopathology 15, 277-295.

Elsabbagh, M. \& Johnson, M.H. (2010). Getting answers from babies about autism. Trends in Cognitive Science 14, 81-87.

Elsabbagh, M., Holmboe, K., Gliga, T., Mercure, E., Hudry, K., Charman, T. ... \& Johnson, M.H. (2011). Social and attention factors during infancy and the later emergence of autism characteristics. Programme of Brain Research 189, 195-207.

Feldman, R. (2007). Parent-infant synchrony and the construction of shared timing; Physiological precursors, developmental outcomes, and risk conditions. Journal of Child Psychology and Psychiatry 48(3/4), 329-354.

Gamliel, I., Yirmiya, M., Jaffe, D.H., Manor, O. \& Sigman, M. (2009). Developmental trajectories in siblings of children with autism: Cognition and language from 4 months to 7 years. Journal of Autism and Developmental Disorders 39(8), 1131-1144. 
Goldstein, M. H., King, A. P. \& West, M. J. (2003). Social interaction shapes babbling: Testing parallels between birdsong and speech. Proceedings of the National Academy of Sciences 100(13), 8030-8035.

Gros-Louis, J., West, M. J., Goldstein, M. H. \& King, A. P. (2006). Mothers provide differential feedback to infants' prelinguistic sounds. International Journal of Behavioral Development 30, 509-516.

Hsu, H., Fogel, A. \& Messinger, D. S. (2001). Infant non-distress vocalization during mother-infant face-to-face interaction: Factors associated with quantitative and qualitative differences. Infant Behavior and Development 24, 107-128.

Jakubowski, K.P. \& Iverson, J.M. (2011). Attention-related communication in interactions between toddlers at high vs. low risk for autism and their mothers. Poster presented at the Biennial Meetings of the Society for Research in Child Development, Montreal, Quebec, Canada.

Kasari ,C., Gulsrud, A., Freeman, S., Paparella, T. \& Hellemann, G. (2012). Longitudinal follow-up of children with autism receiving targeted interventions on joint attention and play. Journal of the American Academy of Child and Adolescent Psychiatry 51(5), 487-495.

Klin, A. (1991). Young autistic children's listening preferences in regard to speech: A possible characterization of the symptom of social withdrawal. Journal of Autism and Developmental Disorders 21, 29-42.

Ko, E.-S. (2012). Nonlinear development of speaking rate in child-directed speech. Lingua, 122, 841857.

Landry, R. \& Bryson, S.E. (2004). Impaired disengagement of attention in young children with autism. Journal of Child Psychology and Psychiatry 45, 1115-1122.

Language Environment Analysis (LENA) system. http://forum.lenafoundation.org/

Ma, W., Golinkoff, R.M., Houston, D. \& Hirsh-Pasek, K. (2011). Word learning in infant- and adultdirected speech. Language Learning and Development 7, 209-225.

Mahdhaoui, A., Chetouani, M., Cassel, R. S., Saint-Georges, C., Parlato, E., Laznik, M-C. ... \& Cohen, D. (2011). Computerized home video detection for motherese may help to study impaired interaction between infants who become autistic and their parents. International Journal of Methods in Psychiatric Research 20. e6-e18.

Masataka, N. (2003) . The onset of language. Cambridge: Cambridge University Press.

Matychuk, P. (2005). The role of child-directed speech in language acquisition: A case study. Language Sciences, 27, 301-379.

Meirsschaut, M., Roeyers, H. \& Warreyn, P. (2011). The social interactive behaviour of young children with autism spectrum disorder and their mothers. Autism 15(1), 43-64.

Meirsschaut, M., Warren , P. \& Roeyers, H. (2011). What is the impact of autism on mother-child interactions within families with a child with autism spectrum disorder? Autism Research 4, 3583667. 
Meyer, S., Jungheim, M. \& Ptok, M. (2011). Child-directed speech: Does it really help language acquisition? $H N O$, 59(11):1129-34.

Mundy, P., Delgado, C., Block, J., Venezia, M., Hogan, A. \& Seibert, J. (2003). A manual for the abridged early social communication scales. University of Miami Psychology Department: Coral Gables, Fl.

Noldus. (2009). The Observer XT: The next generation of observation software. Wageningen, The Netherlands: Noldus.

Ozonoff, S., Young, G.S., Carter, A., Messinger, D., Yirmiya, N., Zwaigenbaum, L. ... \& Stone, W.L. (2011). Recurrence risk for autism disorders: A baby siblings research consortium study. Paediatrics 128(3), 1-8.

Paavola, L., Kunnari, S., Moilanen, I. \& Lehtihalmes, M. (2005). The functions of maternal verbal responses to prelinguistic infants as predictors of early communicative and linguistic development. First Language 25, 173-195.

Parladé, M.V., Johnson, J.L. \& Iverson, J.M. (2010). The effects of parental stress on the emergence and development of joint attention. Presented at International Meeting for Autism Research (IMFAR), Chicago, IL.

Penman, R., Cross, T., Milgrom-Friedman, J. \& Meares, R. (1983). Mothers' speech to prelinguistic infants: A pragmatic analysis. Journal of Child Language 10, 17-34.

Pine, J.M. (1992). Maternal style at the early one-word stage: Re-evaluating the stereotype of the directive mother. First Language 12(35), 169-186.

Rogers, S.J. (2009). What are infants siblings teaching us about autism in infancy? Journal of Autism Research 2(3), 125-137.

Saint-Georges, C. (2011). Dynamic, synchrony, reciprocity and motherese in interactions of infants who will develop autism through family home movies. (Unpublished doctoral dissertation). Université Pierre \& Marie Curie, Paris 6.

Saint-Georges, C., Cassel, R. S., Cohen, D., Chetouani, M., Laznik, M-C., Maestro, S. \& Muratori, F. (2010). What studies of family home movies can teach us about autistic infants: A literature review. Research in Autism Spectrum Disorders 4(3), 355-366.

Saint-Georges C, Mahdhaoui, A., Chetouani, M., Cassel, R.S., Laznik, M-C., Apicella, F. ... \& Cohen. D. (2011). Do parents recognize autistic deviant behavior long before diagnosis? Taking into account interaction using computational methods. PLoS ONE 6(7): e22393.

Saxon, T. F. (1997). A longitudinal study of early mother-infant interaction and later language competence. First Language 17(51), 271-281.

Seidman, I., Yirmiya, N., Alon, R., Ben Yitzhak, N., Lord, C. \& Sigman, M. (2010). Diagnostic outcomes in school age siblings of children with autism. International Public Health Journal 2, 113-124. 
Siller, M.. \& Sigman, M. (2002). The behaviours of parents of children with autism predict the subsequent development of their children's communication. Journal of Autism and Developmental Disorders 32, 77-89.

Siller, M., \& Sigman, M. (2008). Modeling longitudinal change in the language abilities of children with autism: Parent behaviors and child characteristics as predictors of change. Developmental Psychology 44(6), 1691-704.

Singh, L., Nestor, S., Parikh, C. \& Yull, A. (2009). Influences of infant-directed speech on early word recognition. Infancy, 14, 654-666.

Soderstrom, M. (2007). Beyond babytalk: Re-evaluating the nature and content of speech input to preverbal infants. Developmental Review, 27, 501-532.

Spiker, D., Boyce, C.G. \& Boyce, L.K. (2002). Parent-child interactions when young children have disabilities. International Review of Research in Mental Retardation 25, 35-70.

Swenson, L., Fein, D. \& Naigles, L. (2008). The influence of the frequency of maternal speech acts vs. children's responsiveness to those speech acts in typically developing children and children with autism. Poster presented at International Meeting for Autism Research (IMFAR). London, UK.

Tamis-LeMonda, C.S., Baumwell, L.B. \& Cristofaro, T. (2012). Parent-child conversations during play. First Language. Advance online publication. doi: 10.1177/0142723711419321.

Thiessen, E.D., Hill, E.A. \& Saffran, J.R. (2005). Infant-directed speech facilitates word segmentation. Infancy, 7, 53-71.

Tomasello, M. \& Farrar, J. M. (1986). Joint attention and early language. Child Development 57, $1454-1463$.

Trevarthen, C. \& Aitken, K.J. (2001). Infant intersubjectivity: Research, theory and clinical applications. Journal of Child Psychology \& Psychiatry 42, 3-48.

van Geert, P. \& van Dijk, M. (2002). Focus on variability: New tools to study intra-individual variability in developmental data. Infant Behaviour \& Development 25, 340-374.

Venuti, P., Bentenuto, A., De Falco, S., Esposito, G. \& Bornstein, M.H. (2012). Maternal \& paternal speech to children with autism spectrum disorder. Poster presented at International Meeting for Autism Research, IMFAR, Toronto, Canada.

Venuti, P., de Falco, S., Esposito, G., Zaninelli, M. \& Bornstein, M. H. (2012). Maternal functional speech to children: A comparison of autism spectrum disorder, Down syndrome, and typical development. Research in Developmental Disabilities 33, 506-513.

Wan, M. W., Green, J., Elsabbagh, M., Johnson, M. H., Charman, T., Plummer, F. \& the BASIS Team. (2012). Parent-infant interaction in infant siblings at risk of autism: A controlled observational study. Research in Developmental Disabilities 33, 924-932.

Waterhouse, L. (2012). Rethinking autism: Variation and complexity. NY: Academic Press. 
Yirmiya, N. \& Charman, T. (2010). The prodrome of autism: Early behavioral and biological signs, regression, peri- and post-natal development and genetics. Journal of Child Psychology and Psychiatry 51(4), 432-258.

Yoder, P. \& Stone. W. L. (2006). A randomized comparison of the effect of two prelinguistic communication interventions on the acquisition of spoken communication in preschoolers with ASD. Journal of Speech, Language, and Hearing Research 49, 698-711.

Yoder, P. \& Symons, F. (2010). Observational measurement of behaviour. New York: Springer.

Zwaigenbaum, L., Bryson, S., Lord, C., Rogers, S., Carter, A., Carver, L. \& Yirmiya, N. (2009). Clinical assessment and management of toddlers in suspected ASD: Insights from studies of high-risk infants. Pediatrics 123, 1383-1391.

\section{Résumé}

Les aspects fonctionnels du discours adressé au nourrisson (en anglais IDS, « infant-directed-speech ») dans l'interaction en face à face jouent un rôle central dans le développement du nourrisson (Venuti et al. 2012) et contribuent à façonner la réactivité de l'enfant (Goldstein et al. 2003). Cependant, ils ont rarement été examinés et ne font pas l'objet d'un consensus en ce qui concerne les résultats spécifiques pour les nourrissons. Les frères et sœurs nourrissons des enfants atteints d'autisme présentent un risque plus élevé de développer ce trouble caractérisé par des déficiences socio-communicatives et posent des problèmes spécifiques pour les parents en interaction. En basant notre projet sur l'analyse prospective vidéo, notre objectif était double: d'une part, examiner les aspects fonctionnels des styles de discours maternels dans l'interaction des mères avec les jeunes frères et sœurs; d'autre part, analyser la relation entre le style fonctionnel maternel et le développement cognitif, socio-communicatif et langagier. Les résultats montrent des taux significativement plus faibles d'énoncés maternels contingents dans le cas des frères et sœurs à risque, mais des associations significatives entre le discours maternel adressé au nourrisson (IDS) et les résultats des tests réalisés sur les nourrissons dans le cas des dyades typiques uniquement. 